\title{
Experiences of Batswana women diagnosed with both HIV/AIDS and cervical cancer
}

\author{
T Molefe, MSc \\ Division of Nursing and Midwifery, School of Health and Rehabilitation Sciences University of Cape Town \\ SE Duma, PhD \\ Division of Nursing and Midwifery, School of Health and Rehabilitation Sciences, University of Cape Town
}

Kev words

Batswana women; cervical cancer; HIV/ AIDS; chronic emotional pain

\section{Correspondence address}

Division of Nursing and Midwifery

School of Health and Rehabilitation

Sciences

Faculty of Health Sciences

F45 Old Main Building,

Groote Schuur Hospital,

Observatory 7925

Tel:(021) 4066321

Fax:(021) 4066323

Cell: 0824492635

E-mail : Sinegugu.duma@uct.ac.za

\section{Abstract: Curationis 32 (4): 29-39}

The central phenomenon of interest to the authors was the experiences of Batswana women who have been diagnosed with both HIV/AIDS and cervical cancer. They wanted to know how these women and their families coped with the burden of the two 'fatal' diseases. This interest was brought about by the current surge in cervical cancer cases in the country, and the relationship between the two diseases. There is scant literature on the experiences of women with the dual diagnosis of HIV/AIDS and cervical cancer.

The purpose of the study was to explore the experiences of Batswana women who are diagnosed with both HIV/AIDS and cervical cancer. The research question was 'What are the experiences of Batswana women diagnosed with both HIV/AIDS and cervical cancer?' A phenomenological descriptive qualitative research design was therefore appropriate to answer the research question.

Semi-structured interviews and field notes were used to collect data. One-to-one interviews were conducted with six women diagnosed with the two diseases. Both convenience and purposive sampling techniques were used in selection of participants.

The seven procedural steps proposed by Collaizi (1978) were utilized in data analysis as the study was based on the phenomenology approach. The findings revealed that HIV/AIDS and cervical cancer are chronic illnesses that can instill chronic emotional pain. Reactions to diagnosis with these diseases include pain, fear or intense sadness. Coping with these conditions can be facilitated by different strategies such as acceptance, having hope, support from others and positive thinking. Support can come from children, family members, informal or formal groups and health service providers. 


\section{Introduction and background}

According to the Terra Daily (2006: 1), the cancer surge is overwhelming doctors in Botswana. Dr Paleske, the head of the oncology unit in Marina, the largest state-owned hospital, informed Terra Daily reporters (2006: 1) that outpatient visits of female cancer patients increased from 2050 in 2002 to 5650 in 2006. Figures have more than doubled over a period of four years. Dr Paleske linked this dramatic increase with the AIDS crisis in the country, explaining that the cancer surge is caused by HIV, which weakens the body's immune system. He reported that some of the cancers were due to HIV/AIDS while others were aggravated by the same condition. Botswana National Cancer Registry (2005: 7) also reported this relationship, with cervical cancer being the most common cancer among HIV-positive women.

In 1993 cervical cancer was declared an AIDS-defining illness in the World Health Organization (WHO) European region because of the increase of cervical cancer cases in HIV-infected individuals (Bower, Palmier \& Stebbing, 2006: 228; Maso, Serraino \& Franseschi, 2001: 1196). This increase in cervical cancer cases might be due to the drop in the age of onset of the disease. According to Otto (2005: 248) cervical cancer occurred mainly between the ages of 35 and 50 years, but in Botswana it was found that $22 \%$ of the cervical cancer cases occurred before the age of 40 years, with young women of 20-24 years also being diagnosed with the disease (Botswana $\mathrm{Na}$ tional Cancer Registry, 2004: 20).

Being diagnosed with a chronic disease such as cancer or HIV/AIDS can be painful and distressing. A study conducted on African American and Caucasian women indicated several emotions after receiving a diagnosis of cancer. Most of the participants were shocked, fearful and anxious about diagnosis, surgery and treatment. Some experienced anger, but others stated that they were very calm (Lyons \& Shelton, 2004: 4). Similarly, HIV/AIDS patients voice various feelings, such as feeling unloved and uncared for, inner turmoil and fear (Edwards, 2006: 683). A study conducted on HIV-posi- tive mothers also indicated feelings of anger - to the people who had infected them, but also to themselves for allowing it to happen. Some reported that they felt like killing themselves (had suicidal thoughts) (Marcenko \& Samost, 1999: 39).

In a study conducted on African women diagnosed with both HIV/AIDS and cervical cancer in South Africa, a number of emotional experiences were reported. These included fear of death, not wanting to face reality, and fear to leave children behind. Stress and depression and feelings of isolation were also reported. However, most of the women had faith in God and hoped to live long (Maboko \& Mavundla, 2006: 38).

The WHO (2005: 37$)$ reported that patients face many challenges after diagnosis with cancer of the cervix and HIV/ AIDS. The same report identified challenges faced by palliative care patients as pain $(64 \%)$, cough $(39 \%)$, headache $(38 \%)$, weakness $(36 \%)$ and psychological stress $(28 \%)$. Other problems were lack of food, lack of social support, irregular supply of drugs, shortage of clothing and social isolation. Problems revealed in other studies included stigma, unemployment, lack of income or financial resources to cover living and health care costs, inability to do certain household work, and family and friends' inability to adapt to the demands of the illness (Baigis-Smith \& McGuire, 1995: 3; Klee, Thranow \& Machin, 2000: 7).

The above issues formed the basis for this study. The challenges and needs relating to these diseases are usually addressed per disease. There is scant literature on the experiences of women with the dual diagnosis of HIV/AIDS and cervical cancer.

\section{Cancer of the cervix as a diagnosis}

Cervical cancer is the malignant neoplasm which develops at the squamocolumnar junction, the area of the cervix where squamous cells that line the vagina and cover the outer portion of the cervix and the columnar cells that line the endocervical canal meet. These cancer cells are new, abnormal growth of tissue which fails to fulfill its normal function, thereby forming a mass that extends beyond the boundaries of normal tissue (Otto, 2005: 4, 248). Cervical cancer is the seventh most common cancer worldwide, and the second commonest cancer among women. According to Parkin, Bray, Ferlay \& Pisani (2005: 74-108) there were 493000 new cases and 274000 deaths in 2002, with $83 \%$ of the cases occurring in developing countries. Higher incidences were prominent in Sub-Saharan Africa, Melanesia, Latin America and the Caribbean, South-Central Asia and South-East Asia. Mortality rates were much lower than the incidence, with mortality to incidence ratio of $55 \%$. Survival rates varied between regions and prognosis was mostly good in low-risk areas (74.6\% in the US Surveillance Epidemiology and End Results (SEER) Program and $63 \%$ in European registries). Survival rates were also fair in developing countries, where many of the cases were identified at an advanced or late stage (SEER Cancer Statistics Review, 1975-2003; Parkin, Bray, Ferlay \& Pisani, 2005: 74-108; Cancer Facts and Figures, 2006: 20).

Diagnosis with cervical cancer seems to be more distressing than with other cancers because of its nature, beliefs around causality and the treatment modalities involved. A study on African American and Caucasians indicated that patients with cervical cancer were significantly more distressed (x $2=11.58$ ) than patients with breast cancer (Lyons \& Shelton, 2004: 4).

Cervical cancer remains a problem in Botswana, where the prevalence is about $31.9 \%$. It is the most common cancer among black female patients diagnosed with cancer. The number of people living with this disease and the number of deaths seem to be growing alarmingly, just as with HIV/AIDS (UNAIDS/WHO Report on HIV/AIDS 2006: 1).

\section{HIVIAIDS as a diagnosis}

HIV/AIDS is a great threat worldwide. The number of people living with AIDS and the number of deaths caused by this disease is still growing. In 2006 39.5 million people were living with HIV worldwide, an increase of 2.6 million people from 2004 (UNAIDS/WHO Report on HIV/AIDS, 2006: 1).

Sub-Saharan Africa is carrying a heavy 
burden from this epidemic, with twothirds $(63 \%)$ of all adults and children with HIV from this region. Thirty-two percent of all the people living with HIV globally and $34 \%$ of all deaths due to the disease in 2006 were in Southern Africa. Women were the most affected group in Sub-Saharan Africa, with a prevalence of $59 \%$ (UNAIDS/WHO Report on HIV/AIDS, 2006: 10).

Botswana is also experiencing a severe epidemic of HIV/AIDS, with an adult HIV prevalence rate of $24 \%$ (UNAIDS/ WHO Report on HIV/AIDS, 2006: 10). In 2003 AIDS was the major cause of inpatient adult morbidity, with women having a higher prevalence (4135; $52.65 \%)$ than men $(3719 ; 47.35 \%)$. Although females were most affected, inpatient mortality rates indicated a lower death rate among women (1323) than men (1365) (Botswana Health Statistics Report, 2003: 64).

\section{Diagnosis with cervical cancer and HIV/AIDS}

This dramatic increase in the two diseases can be a burden to the patient, family, friends and care-givers as they spend most of their time with these patients. Many HIV/AIDS patients suffer with problems similar to those of cancer patients. According to the WHO (2005: 37), these problems range from pain, dyspnoea, wasting and confusion states to psychological distress and other devastating symptoms. Both of these diseases are still perceived as fatal and the diagnosis is equated with death, and that causes depression and anxiety (WHO, 2005: 38; Jennings, 1997: 829; Dabash, Vajpayee, Jacob, Dzuba, Lal \& Bradley 2005). HIV/AIDS and cancer can also be distressing to the families of those affected, and profoundly impacts on both family functioning and the economic situation (WHO, 2005: 38).

Life stress can negatively affect the health of the women. Stress can also trigger some psychiatric conditions. The stigma and other challenges related to HIV/AIDS can worry patients a lot. Stress had been reported to cause depressive disorders in a study in China where the lifetime rate of major depression was reported as $79 \%$ in a group of HIV-infected individuals, a difference of $75 \%$ from an HIV-negative compari- son group. All the depressive episodes developed six months after receiving the results. Almost half of the depressed HIV-positive patients were also reported to have had suicidal thoughts, and one-third of that group had attempted or planned suicide at one point (Jin, Atkinson, Yu, Heaten, Shi, Marcote, Young, Sadek, Wu, \& Grand, 2006: 273).

Diagnosis with these two diseases does not only stress the patients, it can also stress their families or friends. A study by De Groot et al. (2005: 922) found that cervical cancer had some impacts on the women and also on their partners, with the psychosocial impact of the disease almost the same in both the partners and the affected women. Both also reported disruptions in intimacy, which was defined by spousal relationship and sex life, but women seemed to be more affected than their partners. Edwards (2006: 683) also found that diagnosis of HIV/AIDS has some serious impacts on the relationship of infected women and their partners, with relationship turbulence affecting women's adherence to highly active antiretroviral treatment (HAART) as the women felt unloved and uncared for.

Another huge problem that patients can face is stigma. A study conducted by Simbayi et al. (2007: 1827) revealed that people living with HIV/AIDS in Cape Town experienced a lot of discrimination and internalized AIDS stigma. One in four participants in the study reported that they had never talked to a friend about their HIV status, and one in three was not treated well by their friends and family. More than $40 \%$ of the participants had experienced discrimination due to the HIV infection, and one in five had lost their home (place to stay) or job because of their HIV status. According to Carr and Gramling (2004: 35), stigma can have a negative effect on many aspects of women's lives. They found that women spent endless hours and a lot of energy hiding their secret to avoid condemnation, rejection and pain. Some of participants even delayed seeking health care and avoided family members and friends. Participants in this study said that their greatest fear after diagnosis was not death but the negative reactions of people. Haile et al.
(2002: 79) revealed that patients can also be vulnerable to the moral evaluation of nurses working with them.

Like HIV/AIDS, cervical cancer seems to be one of the stigmatized diseases. A study conducted by Ashing-Giwa $e t$ al. (2004: 713) revealed that the belief that cervical cancer is contagious and sexually transmitted stigmatized the condition. Some religious beliefs also increased the stigma - some women thought they had cervical cancer as a divine punishment. These beliefs delayed seeking health care and had serious negative outcomes, since the women thought that God will heal them and didn't seek medical support.

\section{Problem statement}

According to Botswana National Cancer Registry Report (2005: 8), HIV/AIDS is assumed to be responsible for the increase in the frequency of cervical cancer in Botswana. This report also revealed that the peak age of onset of cervical cancer is falling, and that might be due to the increasing cases of HIV/ AIDS. It was found that $22 \%$ of cervical cancer cases occurred before the age of 40 years. Young women aged 20-24 years were also diagnosed with cervical cancer. However, there is scant literature on the experiences of HIVpositive women who are diagnosed with cervical cancer. Some of the studies found during the literature review indicated experiences of either cervical cancer patients alone or HIV/AIDS-affected women alone. The lack of literature on dual diagnosis can make it difficult for nurses to improve the quality of care for these patients. A study of the experiences of living with the two conditions can highlight women's needs and therefore assist the nurses with their care.

\section{Purpose of the study}

The purpose of the study was to explore the experiences of Batswana women diagnosed with both HIV/AIDS and cervical cancer.

\section{Research question}

What are the experiences of Batswana women diagnosed and living with both HIV/AIDS and cervical cancer?

\section{Objectives}

The objectives of the study were: 
to explore what it is like to be diagnosed and living with both HIV/AIDS and cervical cancer and

- to describe women's experience of living with both HIV/AIDS and cervical cancer.

\section{Methodology}

A descriptive qualitative research design within the phenomenology approach was used to explore the experience of living with the two serious chronic illnesses. This design was appropriate to answer the research question: "What are the experiences of Batswana women diagnosed with both HIV/AIDS and cervical cancer? This is because it is a naturalistic method of enquiry emphasizing an understanding of human experience as it is lived.

Qualitative authors study participants in their own settings in order to interpret phenomena in terms of the meanings people bring to them. This includes a variety of empirical materials such as case studies, personal experience, life stories, observational and visual texts that describe routine and problematic meanings and moments in one's life (Denzin \& Lincoln, 1998: 3; Polit \& Beck, 2006: 16).

\section{The research setting}

All participants were sheltered in an interim home, where they stayed to complete the radiation therapy at a local private hospital. The interim home accommodates cancer patients undertaking treatment at Gaborone Private Hospital and those waiting to be transferred to health facilities in South Africa for further management. A quiet room in the interim home was used. The set-up of the room gave the author and participants enough room and a choice of seating, making the environment comfortable and relaxing.

\section{Population}

The population was all Batswana women diagnosed with both HIV/AIDS and cervical cancer attending the departments of oncology and gynaecology at a tertiary hospital in Botswana.

\section{Sampling}

Sampling is "the process of selecting a portion of the population to represent the entire population and a sample is a subset of the population" (Polit \& Beck 2006: 260). Because qualitative authors are not interested in numbers but in meaning, participants are sought according to experiential fit and by looking for the qualities of a good informant. Experiential fit is where an author searches for participants who have either lived the experience, undergone the experience or observed an individual undergoing the experience (Munhall, 2007:530).

Both convenience and purposive sampling were used. Convenience sampling is the use of readily available participants. Purposive sampling is a judgemental sampling method in which the author selects informative participants or those that best represent the population under study (Polit \& Beck, 2006: 262; Neuman, 2004: 140; Munhall, 2007: 230). The first two participants for the pilot phase were identified by the nursing staff because the author was not familiar with the patients. After the preliminary analysis of data from these two patients, other participants were identified based on 'experiential fit' as part of purposive sampling. Only participants who met the inclusion and exclusion criteria were selected.

\section{Inclusion criteria}

Only participants who met the following inclusion criteria were recruited into the study: (a) Women diagnosed with both cervical cancer and HIV/AIDS and able to speak either Setswana or English and (b) Women within the range of stages 0-IIIB stage of diagnosis of cervical cancer. Stage 0 means there is carcinoma in situ, no regional lymph node metastasis and no distant metastasis, while stage IIIB is where the tumour extends to the pelvic wall and there is regional lymph node metastasis but no distant metastasis (Otto, 2001: 253); (c) Women who had or did not have other chronic illnesses (e.g. high blood pressure or diabetes). An additional criterion was that those who had chronic medical conditions should be well managed.

\section{Exclusion criteria}

Women at the last stage of AIDS; women with cervical cancer stage IV; women at the late stages of both AIDS and stage IV of cancer of the cervix and women with mental illnesses and those who had hearing impairments were excluded from participating in the study.

\section{Sample size}

A sample of six participants was recruited including the two participants who were recruited for pilot purposes. This sample size of six participants is in line with the literature (Morse (1994) cited in Sandelowski 1995: 181). Sandelowski (1995:181) adds that even one case can be enough for an experience to be deemed significant for display. Holloway and Wheeler (2002: 128) state that there are no rigid rules for sample size in qualitative research, and sample size does not necessarily determine quality of the data collected.

\section{Research Setting}

All participants were sheltered in an interim home, where they stayed to complete the radiation therapy at a local private hospital. The interim home accommodates cancer patients undertaking treatment at Gaborone Private Hospital and those waiting to be transferred to health facilities in South Africa for further management. A quiet room in the interim home was used. The set-up of the room gave the author and participants enough room and a choice of seating, making the environment comfortable and relaxing, rather like sitting in a living room at home.

\section{Pilot phase}

A pilot study is " a small scale version, or trial run, done in preparation for a major study" (Polit \& Beck, 2006: 506). Pilot interviews were conducted with the first two participants recruited in preparation for the main investigation. These participants shared similar characteristics with those in the main study, meeting the inclusion and exclusion criteria.

The aim of the pilot study was to improve effectiveness of the author's data collection skills and to strengthen or modify the semi-structured interview guide. As a novice researcher, that helped to gain some experience in interviewing and also to check that the questions were simple, answerable and clear to participants. The pilot interviews were conducted in Setswana, and based on the pilot participants' responses, no changes were made to the interview guide. 


\section{Recruitment and ethical considerations}

After approval from the University of Cape Town, South Africa, and the Botswana Ministry of Health (research unit), the author was given permission to recruit participants by the hospital management. A letter was written to ask the nurses in these departments to assist the author with recruitment as needed. The recruitment period lasted for three weeks, from 24 July 2007 to 10 August 2007. The nurse who was on duty informed potential participants about the study and asked them to indicate whether they were willing to participate. The first two participants were identified by this nurse, and the author was introduced to them. Another three participants who met the criteria were only identified by the author in the third week, and had just been admitted. The last participant was admitted at the end of the third week; she was identified and recruited on the second day of her admission.

After identifying each participant, the author explained the study in detail and the ethical considerations, obtained permission to use the tape recorder and outlined the benefits of participation. The author explained to the participants about her role as a researcher and as a postgraduate student from the University of Cape Town. Information sheet and consent forms were used to explain the content of the research. Each participant was given the information sheet to go through before the next meeting, scheduled for the first interview. Arrangements for the time of the interview were made with each participant. All signed the consent forms before the interviews started.

\section{Data collection}

In line with the purpose of the study, semi-structured interviews, using an interview guide, probes and clarification statements were used to allow for thick description and exploration of the phenomenon. Interview guide and field notes were chosen as data collection methods because they allowed participants to describe their experiences in detail, making it easier for the author to understand the phenomenon under investigation. Polit and Beck (2004: 341) explain that semi-structured interviews help to ensure that a specific set of top- ics are covered in the interview.

Field notes are observations and interpretations made by the author in the field. They may include daily logs, but in a broad way, and are also more analytical and interpretive. They give the author's feelings about the research process and give interpretations to observations (Polit, Beck \& Hungler, 2001:283)

\section{Limitations of the study}

Since the author used convenience sampling, the findings must be applied with caution since they might not represent all Batswana women diagnosed with HIV/AIDS and cervical cancer. The author explained the methodology used in this study in detail so that the findings can be applied appropriately. Another limitation was the exclusion of people with disabilities such as hearing impairments due to the lack of sign language facilities.

\section{Data management and analysis}

All interviews were transcribed verbatim by the author immediately after completion of each interview. This was done to allow for detailed completion of participants' responses following the interview. The transcription process also helped the author to be immersed in the data and to prepare for organization of the data. Once all interviews were fully transcribed and printed out, the author kept the right and left margins for comments.

The transcribed interview documents were saved in Microsoft Word computer files for each participant in both the hard drive and on a flash disk for backup purposes. This ensured prevention of possible loss of data in case the computer was stolen or the main file destroyed. All data pertaining to the participants and the study were kept in a safe and secure environment for security reasons and destroyed after the completion of the study.

\section{Data analysis}

The seven procedural steps proposed by Collaizi (1978) cited in Polit and Beck (2006:410) and Holloway and Wheeler (2002:181), based on Husserl's philosophy, were used to guide data analysis.
As a novice researcher, this framework was useful in explaining the interpretations of the descriptions from the participants.

Collaizi's procedural steps used in data analysis included the following:

1. Reading all protocols (participants' descriptions) to acquire a feel for them

2. Reviewing each protocol to extract significant statements; i.e. returning to each description and extracting phrases or sentences directly pertaining to the investigated phenomena.

3. Spelling out the meaning of each significant statement (i.e. formulated meanings).

4. Organizing the formulated meanings into clusters of themes:

a) Refer these clusters back to the original protocols to validate them.

b) Note any discrepancies among or between the various clusters, avoiding the temptation of ignoring data or themes that do not fit.

5. Integrating the results into an exhaustive description of the investigated topic.

6. Formulating an exhaustive description of the phenomenon under study in as unequivocal a statement of identification as possible.

7. Asking participants about the findings as a final validating step.

At the end of data analysis eight themes emerged from data. These were as follows:

1. Initial deep hurting pain

2. Fear for the future

3. Intimate loneliness

4. Blaming others

5. Hope that things will improve

6. Forced acceptance

7. Support from others

8. Thankful to be alive

The author examined the descriptions of the meanings of the lived experiences of Batswana women diagnosed with HIV/AIDS and cervical cancer to formulate a statement describing the meaning of the phenomenon. At this stage the author also engaged with the research supervisor (a second author), 
who went through the clustered themes and supportive raw data together with the author. Once both were satisfied that the emerging themes were a reflection of the data describing the lived experiences of the Batswana women, the author went back to the participants with the results to validate whether the descriptions matched their own experiences. This was one of the steps taken to ensure trustworthiness of the study, and is known as member checking (Polit \& Beck, 2006:332).

\section{Trustworthiness}

For trustworthiness of the study, the following were addressed accordingly.

\section{- $\quad$ Credibility}

This refers to the truthfulness of the data and the interpretations made. It emphasizes carrying out the investigation in such a way that people can easily believe the findings. (Miles \& Huberman, 1994: 278; Holloway \& Wheeler, 2002: 255; Polit \& Beck, 2006: 332). The author described all of the procedures used in conducting the study, including explaining the research setting as well as the data analysis methods used, for the reader to be able to make appropriate judgements about the degree of fit, and/or to use the same procedures in order to replicate the study under different circumstances if deemed necessary. The author kept up constant interaction with her supervisor during all levels of conducting the study, from inception of the research idea, to the proposal writing stage, through data collection and during data analysis. The research supervisor is an experienced qualitative researcher. This was also viewed as peer debriefing, defined as the review of all the processes of the research project by a second person knowledgeable in the same field (Miles \& Huberman, 1994: 278; Polit \& Beck, 2006: 332).

Member checking was conducted as the final step of data analysis. This involved going back to the participants with the results to validate whether the description matched their own experiences (Polit \& Beck, 2006: 332). There were no disagreements on the identified themes.

\section{- Confirmability}

This looks at objectivity or neutrality of the study. (Miles \& Huberman, 1994:
278; Polit \& Beck, 2006: 336). A research supervisor trained in qualitative research followed the path of the author to see how the themes and interpretations were arrived at to maintain objectivity and neutrality of the study.

\section{- Transferability/external validity}

This looks at the extent to which the findings can be transferred or generalized to other settings or groups (Polit \& Beck, 2006: 332). That was accomplished by describing the characteristics of the original sample in order to allow for adequate comparisons with other samples when necessary.

\section{- Dependability}

This refers to consistency and stability of data. It focuses on findings, on whether the research questions were clear, and whether the aresearcher's role and status were thoroughly described (Polit \& Hungler, 1995: 430). Dependability was ensured by conducting a pilot study to determine whether the research questions and the semistructured interview were clear before the author proceeded to the main study. Member checking, which involved provision of feedback to the study participants and back from the participants to the author regarding data, confirmed this and convinced the author that there was no bias on reporting of the results.

\section{Findings}

The findings are described according to each of the identified cluster of themes.

\section{Initial deep hurting pain}

This theme was derived from the experiences of extreme or profound mental suffering that these women indicated that they had gone through. According to them, diagnosis with the two diseases was one of the most tragic things that had happened to them. One participant conveyed the depth of the pain as follows:

"[big sigh)]... It bothers me a lot. It's like I am being chopped with three axes in three different places at the same time. It's a big problem".

This clearly showed how painful it was to be suffering from the different chronic illnesses.

Another participant had this to say:
"At first I was so deeply hurt but at the end I just gave up. I also wanted to do a hysterectomy because I was suffering. Hey! I really suffered in life."

Another expressed her initial deep hurting pain as follows:

"I was so stressed at first and it was not easy, but I am better now. These things come step by step. The first experience can be so unbearable but that improves with time. These diseases can stress an individual a lot."

\section{Fear of the future}

This theme was identified from participants' expressions of unpleasant emotions or anxiety experienced in anticipation of what will happen in future with regard to their conditions. This included initial fear of dying and of leaving their children. One participant expressed her fear of the future as a great concern about her eldest son, who was very naughty:

"My main problem is with my firstborn child. [Quietness, crying] I am concerned that no one will take care of him if I die because he doesn't pay attention to anything that my family members say to him. I just don't know how he will survive if I don't recover. I am worried that if I die before he finishes his studies he will suffer. He doesn't have manners."

One would have thought that this woman would care less about that troublesome child, but as a mother she was even more worried about the fact that no one would like to take care of that boy in future, given his current behaviour.

One participant described her fear of the future and what might happen as follows:

"I was once scared and decided to negotiate for adoption of my children and thought of selling all my cattle. I even gave away my clothes."

Another participant was not only scared for the children but was also scared that the diseases might lead to certain physical impairments. Her fear was illustrated as below:

"I am scared that they [both diseases] might kill me at night. When I have a backache like now, I just think that it might get worse leading to paralysis. I am always psychologically disturbed." 


\section{Intimate loneliness}

Although most of the women reported receiving a lot of support from their families, they were still disturbed by the fact that they couldn't secure good intimate interpersonal relationships. Some of the women had to deal with the loss of their husbands or partners, and that made it hard for the women to cope, leading to a certain amount of grief. Some losses were due to death while others came as a result of abandonment by partners after diagnosis with the diseases. These women showed that it was not easy to secure new relationships, since it was hard to trust again or to start all over again given their conditions.

One participant expressed her intimate loneliness as below:

"I had a lot of challenges in life including pain of new diagnosis and loss of a partner who treated me badly. Although this is the case, I still need a man in my life, but not my ex-partner. My main wish now is to stay with my kids even if I don't find another partner."

For another participant, the intimate loneliness was expressed clearly as below, indicating the need for a supportive intimate interpersonal relationship:

"I do get lonely sometimes but I just accept it like that. I know that I can still have a partner although he will stress me. What's the use of dating someone who can't even take good care of me?"

\section{Blaming others}

This theme was developed from expressions that demonstrated how women diagnosed with HIV/AIDS and cervical cancer linked their tragedy to or blamed it on others, including their intimate partners and health service providers. Some women even blamed themselves for trusting someone who later let them down. This theme was further broken down into three sub-themes: blaming the husband or men in general; blaming herself; and blaming health service providers.

\section{Blaming husband/ men in general}

There were feelings of considerable anger elicited in cases where infidelity was known to have occurred, and some women re-experienced the feelings as- sociated with this infidelity:

"I was not promiscuous. I think I just got infected at home. Since I met my partner I have not dated anyone else. All my children are his, even those who are late [deceased]. He is sure of that. $\mathrm{He}$ is the one who was dating a lot of women behind my back. He is the one who brought all this to me."

Another participant was angry and attributed her conditions to her late husband:

"My husband died in 2000. He is the one who infected me. He was diagnosed with this disease but didn't tell me. When he was about to die he told me to go to the hospital but he didn't tell me that he had the disease. Even this cancer is because of him and his diseases."

\section{Blaming herself}

Some of the participants blamed themselves for letting the diseases happen to them, as indicated below:

"If only I stayed and not participated in premarital sex! The church discourages that. They discourage sex before marriage. I started early and now I am paying."

Another participant blamed herself for letting herself get so sick without seeking medical advice:

"My sisters used to discuss a lot of things like HIV/AIDS, TB, etc. before I tested. I couldn't bear that and it was so painful. I always asked myself why they did that. If I could have listened to them and got the first HIV test results I wouldn't have been so sick."

\section{Blaming health service providers}

Statements used to develop this subtheme indicated that women felt that their situations would not have been so bad if they got 'proper' and 'timely' assistance. One participant reported and blamed the unpleasant behaviour of health workers:

"I still blame health workers at the local clinic. If they could have helped me when I reported the vaginal discharge I had, maybe I would not have had cancer and AIDS. There is something that really upset me in one of the hospitals I went to. I had the heavy discharge and the doctor said the problem is brought by the fact that I didn't maintain a very good hygiene, instead of checking why. I am sure it was the beginning of cancer. If only he checked me

Another participant had this to say: "I went to the clinic in 1997 to do a Pap smear test and they said it was not possible to have it done on that day. If I could have done it then, maybe $I$ wouldn't be having cervical cancer now. Perhaps they could have seen it and prevented me from having the sore in my womb that resulted in this and AIDS."

\section{Hope that things will improve}

Most participants indicated that they hoped that things would improve. This hope rested on medical treatment, doctors or God. They didn't only express their positive hope in terms of doctors and treatment, but also on some of the things that they had lost hope in, like traditional medicine and herbal products. For technical purposes this theme was also divided into sub-themes.

\section{Hope in medical treatment}

Participants who had long been on ARVs and just started on cervical cancer treatment hoped that the treatment would also prolong their lives, just as the HIV treatment did. Even those who had not started on any treatment were hopeful that the treatments for both diseases would prolong their life, and they were eager to start as soon as possible. (These were participants who were still undergoing tests like CD4 count monitoring and others to identify if they were fit to be started on treatment.)

-One of the participants indicated her hope as follows:

"I have not been to any infectious disease clinic yet, at least to start ARVS. Once I start that, I hope that I will be better."

Other participants had this to say:

"My hope increased when I started ARV treatment. Sometimes I would lose sight on the way to the clinic to take TB treatment, but I decided that I will do everything I can because I wanted treatment."

"I will just be happy if I get treatment and get healed. I just wish they [HIV and cancer medications] can both help me. The HIV treatment has already prolonged my life and I just wish that 
God can help me with this one that I have just started too."

\section{Hope in doctors}

Most of the participants revealed that since there was nothing they could do, they put their hope in the doctors, and were dedicated to following all of the instructions from the doctors:

"I just accepted that there is nothing I can do. I have the diseases. I just put my last hope on doctors. I know they can help me."

"God will help us and the doctors will also do their best."

One stated:

"I don't believe on what people say, but rather on what the doctor says."

Another participant expressed her hope as below:

"I prayed to God and only if I can follow the doctor's prescriptions I will be better."

\section{Hope or belief in God}

All participants revealed their great hope or belief in God. They repeatedly expressed how God will help them. Although they had a lot of hope in the doctors and the treatment, these women expressed how they prayed to God to strengthen the effectiveness of the treatment:

"God will always be there for me and he will heal me. I am just looking upon him for help."

For another participant the grace of God was explained in relation to past experience:

"I concluded that if I managed to live with HIV/AIDS God will help me and I will also overcome cervical cancer"

One had this to say:

"I just pray that God can help me and let me live longer to see my children grow."

\section{Hope (loss of) in traditional medicine or herbal products}

The participants also expressed their loss of hope in traditional medicine and herbal products compared to modern medicine as part of their experiences. Some participants reported having used traditional medicine and/or herbal products in the early years of their diagnosis but their conditions didn't improve.
The following excerpts express their loss of hope in these products:

"I want to encourage other women to visit the clinics for help, it's nothing... They should not focus on traditional medicine. It doesn't help. My father was a pastor for a Zion church and he once told me that I was given something to poison me (sejeso). He gave me some traditional medicine to take. After some time I was diagnosed with TB. Hey! I really suffered in life. My mum also gave me traditional herbs to 'steam or heat the womb' [laughing]. It didn't work and that didn't even stop the abdominal pains and the diarrhea."

"I tried some herbal Chinese products but I have now discovered that I am just wasting money."

\section{Forced acceptance}

This theme was developed to describe how the women tried to deal or cope with their situation of a diagnosis with both HIV/AIDS and cervical cancer in order to move on with life. The author used the word 'forced' to indicate how they were compelled to accept the situation that they were in, since it was beyond their control. That is why most of them said they have accepted the situation - because they knew that without accepting it they wouldn't come to terms with their tragedy.

The following extracts show what the participants meant by accepting their situation:

"I said to myself, 'hey! What is it that can be done? I just have to accept the situation as it is'. Nothing can be done. I needed to accept the situation as it was. I just needed to admit the fact that I needed treatment for cancer, ARVs and treatment for hypertension as well."

"At the end I just gave up. I just accepted that there is nothing that I can do, I have the diseases. I have accepted the situation as it is. Listening to the news helped me to accept the fact that it's a disease like any other disease. Nowadays I am not even ashamed of taking the pills anywhere."

"I had given up in life because I didn't know my main ailment. It was difficult at first but at the end I forced myself and just said, God I have accepted, there is nothing I can do."

Another participant said:

"It was not easy at first but I am fine now. I wish to have money to start a business so that I can build a house for my children. If I die ... you can never know what this world has for you ..."

\section{Support from others}

This theme was developed from the different kinds of support, assistance or encouragement that the participants received from others, including financial, emotional and even physical support. The support that these women got helped them to cope with the challenges of the diseases, and for some it even facilitated acceptance of their situation.

The following extract indicates support that was received from children:

"I don't have any problems now and my children always remind me to take the pills."

This extract illustrates support received from a mother and other family members:

"My mother took care of me when I was very ill. So I knew the importance of letting her know about my illnesses so that she could take care of herself as a care-giver. My sisters also gave me a lot of support. They made sure that I got the right food and that I don't overwork my body at any time. They tried all their best to show me that I am still their sister and that they love me. They take care of me and my children since I am not working. I am their burden together with my children."

\section{Grateful to be alive}

Although most of the participants were so worried about their conditions, some expressed gratitude for things such as being given treatment and other positive things which brought a smile to their faces:

"I am just thankful that we are able to get treatment for both diseases. I have long started ARVs and now I have been sent here for cervical cancer treatment."

Another expressed her relief by mentioning how things changed after disclosing about her conditions to her children: 
"My first child was not performing well at school but after that she started to study hard and she is now better. Even at home they are always trying their best to behave well. For that I am grateful. Perhaps they realized that if I die, they will be nothing."

Although diagnosis with the two illnesses was traumatic, one participant expressed her happiness at being alive in order to see her children grow:

"It is so painful but we told ourselves that we will take this treatment in order to raise our children. I am happy that I am always there to assist them as necessary."

\section{Serendipitous discoveries}

The themes "connection between the two diseases" and "role of the media in screening" was discovered serendipitiously and is discussed below for the completeness of the findings.

\section{Connection between the two diseases}

Some participants expressed the connection of the two diseases as an intertwined single condition. Others clearly related to the two conditions as two separate diseases which did not have an influence on one another.

Of those who saw a connection or relationship between the two conditions, one indicated the association by relating the death of her children to cervical cancer:

"When the doctor told me that I had cervical cancer, I thought that all my babies were conceived with the presence of cervical cancer and that affected them. That is why they all died with the diagnosis of HIV. It is clear that both conditions killed my babies and are going to kill me sooner or later"

Another participant expressed it as follows:

"I just told all of them so that they can be aware of my condition of the AIDS in the cervix. In that way when AIDS kills me everybody will think it is cancer - and yes, it will be it too."

For others there was no association between the two conditions and they always addressed them as two differ- ent diseases which did not influence each other:

"It was not easy too when I was told that I had cervical cancer. I got better after intense counselling from the clinic. I noticed that it is just like any other condition. I concluded that if I managed to live with HIV/AIDS God will help me and I will also overcome cervical cancer."

\section{Role of the media in screening}

Another serendipitous discovery in the study of women diagnosed with both HIV/AIDS and cervical cancer was the importance ascribed to the media in teaching women about the importance of screening for cervical cancer and HIV:

"I knew of cervical cancer and the Pap Smear test before. Ilearnt about it from the radio but I didn't have an idea of how somebody can get it. Because of that little information I decided to test and the results came positive."

For another participant a research study unexpectedly helped her to discover that she had cervical cancer:

"When I went for a check up in order to start ARV treatment I met one lady who was doing research. She asked if there was anything bothering me and I told her about my abnormal vaginal discharge that didn't respond to treatment. She advised me to do a Pap smear and that's when she gave me a specimen form to take to the nurses for the test."

\section{Discussions and recommendations}

The first three themes that emerged most strongly when discussing the experience of living with the two illnesses - deep hurting pain, intimate loneliness and blaming others - indicated some of the impacts of the illnesses. Consistent with the findings of the current study, Maboko and Mavundla (2006: 27) revealed that the experience of being diagnosed with HIV/AIDS and cervical cancer can have impact on the women.

Considerable attention has also been given to the impact of either HIV or cervical cancer alone in a number of studies (Ahlstrom, 2007: 81; PelcastreVillafuerte, Tirado-Gomez, MoharBetancourt \& Lopez-Cervantes 2007: 3; De Groot et al., 2005: 922; Ashing-Giwa et al., 2004: 3; Lyons \& Shelton, 2004: 13).

The findings revealed that participants experienced extreme emotional pain following the diagnosis with the two illnesses. For some participants the deep hurting pain was experienced as a continuous process, while for others it was experienced as intermittent pain triggered by certain factors at different times. These findings are similar to those in the study by Ahlstrom (2007: 81 ), who reported that diagnosis with a chronic illness can lead to chronic sorrow of a substantial degree.

The deep emotional pain was also shown by the report of the First Nations of the Quebec and Labrador Health and Social Services Commission (2004: 43). In this report HIV/AIDS was identified as one of the chronic diseases which can lead to an extreme experience of deep emotional pain. The same report explained that emotional pain comes from the intense spiritual or psychological suffering, and can lead to physical symptoms and difficulty in coping. Just like HIV/AIDS, some studies also reveal great psychological disturbance after diagnosis with cervical cancer (Ashing-Giwa et al., 2004: 3; Lyons \& Shelton, 2004: 13). The latter studies reveal that women diagnosed with cervical cancer had negative psychological reactions such as shock, depression and anxiety.

A study by Ahlstrom (2007: 79) also concurred with the results of the present study that diagnosis with these diseases may lead to intimate loneliness due to abandonment by partners. Ahlstrom revealed that divorce was viewed as a traumatic event - even in cases where the divorce happened before diagnosis with a chronic illness. Participants in the same study attributed divorce to diagnosis with their chronic illnesses. In their study on women diagnosed with cervical cancer, Ashing-Giwa et al. (2004: 3) also showed that those women who still had sexual desires did not find it easy to secure relationships.

A considerable amount of blame was placed on health service providers, since the women believed that if they could have been assisted well in advance, they wouldn't have got HIV/ AIDS and cervical cancer. This is con- 
trary to the findings of Karasz, McKee and Roybal (2003: 199), which reported dissatisfaction with care without blaming health service providers.

Coping with a chronic illness can be very difficult. In their experiences of being diagnosed with HIV/AIDS and cervical cancer, Batswana women coped in different ways. The experience seemed to have closed doors in certain areas of the women's lives, but opened doors to other areas. Important coping strategies identified were placing hope in treatment or God, acceptance, support and thankfulness for being alive.

The findings from the current study highlight the need for more research on the experiences of women diagnosed with HIV/AIDS and cervical cancer in Africa. To improve the quality of life of these women there is a need for better documentation on living conditions, and in-depth descriptions of culturally appropriate interventions on issues relating to diagnosis.

It is recommended that health workers be trained in dealing with issues relating to cervical cancer and HIV/AIDS in order to minimize psychological impact on the women. Incorporating the findings of this study into the curriculum and in-service education addressing issues on HIV/AIDS and cancer is essential. Nurses caring for these patients can use the results to assess and manage their patients in a comprehensive and multidisciplinary manner as well as understanding why these patients behave in the way they do. The findings can also be utilized to design effective community-based programmes for these women based on the knowledge of the experiences and meaning of being diagnosed with both HIV/AIDS and cancer of the cervix.

\section{Conclusion}

HIV/AIDS and cervical cancer are chronic illnesses that can instill chronic emotional pain, just as with other chronic illnesses. Reactions to diagnosis with these diseases include pain, fear or intense sadness. Support can come from children, family members, informal or formal groups and health service providers.

\section{References}

AHLSTROM, G 2007: Experiences of loss and chronic sorrow in persons with severe chronic illness, Journal of Nursing and Health Care of Chronic illness in Association with Journal of Clinical Nursing [Online], Vol. 16, No. 30, pp76-83. Available:http// www.blackwell-synergy.com $\left[10^{\text {th }} \mathrm{Dec}\right.$ 2007].

ASHING-GIWA, KT; KAGAWASINGER, M; PADLLA, GV; TEJERO, JS; CHHABRA, R; MATINEZ, L \& TUCKER, BM 2004: The impact of cervical cancer and dysplasia: A qualitative, multiethnic study. Psycho-oncology [Online], Vol. 13, No. 10, pp709-728. Available: http://web.ebscohost.com [2nd June 2007].

BAIGIS-SMITH, J \& MCGUIRE, DB 1995: Healthcare needs of HIV-infected persons in hospital, outpatient, home and long-time care. JANAC [Online], Vol. 6, No. 6. Available: http:// www.sciencedirect.com $\left[16^{\text {th }}\right.$ October 2007].

BOTSWANA HEALTH STATISTICS REPORT 2003: Central Statistics Office. Ministry of Health. Gaborone.

\section{BOTSWANA NATIONAL CANCER} REGISTRY REPORT 2004: Community Health services Division, Ministry of Health. Gaborone.

\section{BOTSWANA NATIONAL CANCER REGISTRY REPORT 2005: Commu-} nity Health services Division, Ministry of Health. Gaborone.

BOWER, M; PALMIER C \& STEBBING, J 2006: AIDS-associated malignancies. Cancer Therapeutics. [Online], Vol. 1, pp221-234. Available: http://www.sciencedirect.com [ $16^{\text {th }}$ October 2007].

CANCER FACTS \& FIGURES 2006: American Cancer Society. Atlanta. Available: www.cancer.org [29 ${ }^{\text {th }}$ August 2006].

CARR, RL \& GRAMLING LF 2004: Stigma: A health barrier for women with HIV/AIDS. Journal of the Nurses association in AIDS care [Online], Vol. 15, No. 5, pp30-39. Available: http:// www.sciencedirect.com [26 ${ }^{\text {th }}$ September 2007].

DABASH, R; VAJPAYEE, J; JACOB,
M; DZUBA, I; LAL, N; BRADLEY, J \& PRASAD, LB 2005: A strategic assessment of cervical cancer prevention and treatment services in 3 districts of Uttar Pradesh, India. Journal of reproductive Health [Online], Vol.2 (no. 11) Available: http://www.reproductivehealth-journal.com/content $/ 2 / 1 / 11$ [October $5^{\text {th }} 2006$ ].

DE GROOT,JM; MAH, K; FYLES,A; WINTON, S; GREENWOOD, S; DEPETRILLOS,AD \& DEVINS, GM 2005: The psychosocial impact of cervical cancer among affected women and their partners. International Journal of Gynaecological Cancer. [Online], volume15, pp918-925. Available: http:// www.blackwell-synergy.com [26 ${ }^{\text {th }}$ Feb 2007].

DENZIN, NK \& LINCOLN, YS 1998: Strategies of qualitative inquiry. Thousands Oak. Sage Publications.

EDWARDS, LE 2006: Perceived social support \& HIV/AIDS medication adherence among African American women. Qualitative Health Research. [Online], volume 16 (Issue 5), pp679691. Available: http://qhr.sagepub.com [23 ${ }^{\text {rd }}$ Feb 2007].

FIRST NATIONS OF QUEBECAND LABRADOR HEALTHAND SOCIAI. SERVICES COMMISSION 2004: Coping with HIV/AIDS. [Online]. Available: www.cssspngl.com $\left[10^{\text {th }} \mathrm{Dec}\right.$ 2007].

HA ILE, BL; LANDRUM, PA; KORTABA, JA \& TRIMBLE, D 2002: Inner strength among HIV-infected women: Nurses can make a difference. Journal of the association of nurses in AIDS care. [Online], Vol. 13, No. 3, pp74 80. Available: http:// www.sciencedirect.com [26 September 2007].

HOLLOWAY, I 2005: Qualitative research in health care. Berkshire. McGraw-Hill Education.

HOLLOWAY, I \& WHEELER, S 2002: Qualitative research in nursing. $2^{\text {nd }}$ Edition. Oxford. Blackwell Publishing Company.

JENNINGS, KM 1997: Getting a Pap smear: Focus group responses of African American \& Latina Women. Oncol- 
ogy Nursing Forum. [Online], Vol.24 (no. 5) pp827-835.

JIN, H; ATKINSON, H; YU, X; HEATEN, RK; SHI, C; MARCOTTE, TP; YOUNG, C; SADEK, J; WU Z \& GRAND, I 2006: Depression and suicidality in HIV/AIDS in China. Journal of affective disorders. [Online], Vol. 94, pp269-275. Available: http:// www.sciencedirect .com $\left[17^{\text {th }}\right.$ October 2007].

KARASZ, A; MCKEE, MD \& ROYBAL, K 2003: Women's experiences of abnormal cervical cytology: Illness representations, care processes and outcomes. Annals of family medicine [Online], Vol. 1, No. 4, pp196-202. Available: www.sciencedirect.com [ $2^{\text {nd }}$ June 2007].

KLEE, M; THRANOW, I \& MACHIN, D 2000: Life after radiotherapy: The psychological effects experienced by women treated for advanced stages of cervical cancer. Gynaecologic Oncology [Online], Vol. 76, pp5-13. A $v$ a i l a b l e : h t $t$ p:// www.sciencedirect.com $\left[16^{\text {th }}\right.$ October 2007].

LYONS, MA\& SHELTON, MM 2004: Psychosocial impact of cancer in lowincome rural/urban women; phase II. Journal of Rural Nursing and Health Care. [Online], Volume 4 (Issue 2). Available: http://www.rno.org/journal/issues/vol-4/issue-2/Lyons_article.htm [10th Feb 2006].

MABOKO, E 2005: The experience of African women diagnosed with HIV/ AIDS and cervical cancer. Available: http://etd.unisa.ac.za/ETD- db/thesis/ available/etd-09222005-110555/ unstricted/06chapter 5 .pdf [Feb 28 ${ }^{\text {th }}$ 2007].

MABOKO, E \& MAVUNDLA, TR 2006: The experiences of African women diagnosed with both HIV/AIDS and cervical cancer. African Journal of Nursing and Midwifery. Vol. 8, No. 1. $38-42$

MARCENKO, MO \& SAMOST, L 1999: Living with HIV/AIDS: The voices of HIV positive mothers. Available: http://web.ebscohost.com/ehost/ detail .vid $=1 \&$ hid $=103 \&$ sid $=\ldots\left[\right.$ Feb $23^{\text {rd }}$
MASO, DL; SERRAINO, D \& FRANCESHI, S 2001: Epidemiology of AIDS-related tumors in developed and developing countries. European Journal of Cancer. [Online], pp11881201. Available: http://www.scince direct.com [16 ${ }^{\text {th }}$ October 2007].

MILES, MB \& HUBERMAN, MA 1994: Qualitative data analysis. London. Sage Publications.

MUNHALL, PL 2007: Nursing Research: A qualitative perspective. $4^{\text {th }} \mathrm{ed}$. Boston: Jones and Bartlett Publishers.

NEUMAN, WL 2004: Basics of social research; Qualitative and quantitative approaches. Boston. Pearson Education, Inc.

OTTO, SE 2001: Oncology Nursing. $4^{\text {th }}$ ed. St Louis. Mosby Inc.

PARKIN, DM; BRAY, F; FERLAY,J \& PISANI, P 2005: Global Cancer Statistics 2002, Cancer Journal for Clinician. [Online], volume 55, pp 74-108. Available: http:// CAonline.AMcancerSoc.org [ $8^{\text {th }} \mathrm{Au}$ gust 2006].

PELCASTRE-VILLAFUERTE, BE; TIRADO-GOMEZ, LL; MOHARBETANCOURT, A \& LOPEZ-CERVANTES, M 2007: Cervical Cancer: A Qualitative study on subjectivity, family, gender $\&$ health services. Reproductive Health [Online], Vol. 4, No. 3. Available: http://www.reproductivehealth-journal.com/content/4/1/2 [5th Dec 2007].

POLIT, DE \& BECK, CT 2004: Nursing research; Principles and methods. $7^{\text {th }}$ ed. Philadelphia: Lippincott Williams \& Wilkins.

POLIT, DE \& BECK, CT 2006: Essentials of nursing research; Methods, appraisal and utilization. $6^{\text {th }}$ ed. Philadelphia: Lippincott Williams \& Wilkins.

POLIT, DE; BECK, CT \& HUNGLER, BP 2001: Essentials of nursing research; Methods, appraisal and utilization. $5^{\text {th }}$ ed. Philadelphia: Lippincott Williams \& Wilkins.

POLIT, DF \& HUNGLER, BP 1993:
Essentials of nursing research; Methods, appraisals and utilization. $3^{\text {rd }}$ ed. Philadelphia. Lippincott Raven Publishers.

POLIT, DF \& HUNGLER, BP 1997: Essentials of nursing research; Methods, appraisals and utilization. Philadelphia. J.B. Lippincott Company.

SANDELOWSKI, M 1995: Focus on qualitative research: Sample size in qualitative research. [Online], volume 18, pp 179-183. Available: http:// ww w. med.um i ch.edu/c s p/ course $\% 20$ materials/fall\%202005/ forman-focus [27th March 2007].

SEER CANCER STATISTICS REVIEW, 1975-2003: National Cancer Institute. [Online] Available:http:// Seer.cancer.gov/CSR/1975_2003 [9th Feb2007].

SIMBAYI, LC; KALICHMAN, S; STREBEL,A; CLOETE,A; HENDA, N \& MQEKETO, A 2007: Internalized stigma, discrimination and depression among men and women living with HIV/AIDS in Cape Town. Social Science \& Medicine [Online], Vol. 64, pp1823-1831. Available: http:// www.sciencedirect.com [26 September 2007].

TERRA DAILY 2006: Cancer surge overwhelming AIDS crisis in Botswana [Online]. Available: http:// terradialy.com [ $8^{\text {th }}$ October 2007].

UNAIDS/WHO REPORT ON HIV/ AIDS 2006: Sub-Saharan Africa/2006 AIDS epidemic update. [Online]. Available:http://www.unaids.org/en/ HIV_data/epi2006/ [22 ${ }^{\text {nd }}$ Feb 2007]

WHO 2005: Project on palliative care. [Online]. Available: http:// www.who.int/cancer/palliative/ africanproject/en/endex.html [28th Feb 2007]. 